\title{
Students' Metacognition Skills in Physics Problem Solving Based on Epistemological Beliefs
}

\author{
Jusman Mansyur \\ Department of Mathematics and Science Education \\ Universitas Tadulako \\ Palu, Indonesia \\ e-mail: jusman_mansyur@untad.ac.id
}

\author{
Wiji Lestari \\ SMP Negeri 2 Sigi \\ Sigi, Indonesia
}

\author{
I Komang Werdhiana \\ Department of Mathematics and Science Education \\ Universitas Tadulako \\ Palu, Indonesia \\ Muh. Rizal \\ Department of Mathematics and Science Education \\ Universitas Tadulako \\ Palu, Indonesia
}

\begin{abstract}
This research applied qualitative research to elicit and describe students' metacognitive skills in physics problem solving based on their epistemological beliefs. Subjects of this research were the tenth-grade students of a high school in Palu. The subjects were in three categories, i.e: sophisticated, moderate and naïve. The instruments of this research consisted of epistemological beliefs questionnaire (EBAPS), test for physics problem solving, and interview protocol. The data of the problem solving and metacognition was collected through thinking-aloud activity. The data were analyzed by the descriptive method. Based on the data analysis, it could be concluded that students with sophisticated epistemological beliefs showed all main categories and elements of metacognition skills. All elements were not shown by the other two student categories.
\end{abstract}

Keywords-Epistemological beliefs, Metacognition Skills, Problem Solving.

\section{INTRODUCTION}

Individuals' beliefs about knowledge and knowing have been paid attention of educational psychologists during the last two decades. They recognized an importance of the role of belief in the learning process [1]. Beliefs about the nature of knowledge (called epistemological beliefs) have been linked to numerous aspects of learning, particularly among college and high school students [2]. Students' epistemological beliefs in general related to some aspects of the learning, such as conceptual change[3], intrinsic motivation [4] [5], and academic achievement [6].

Perry is who first studied about the epistemological beliefs. He illustrated epistemological beliefs as individual perspective in defining the knowledge, limitation and precision, and its acquisition [7]. Epistemological beliefs in research on learning showed how the knowledge constructed and evaluated [8]. Epistemological beliefs generally closed to the term of "naïve" and "sophisticated". Some researchers used "novice" and "expert". Individuals who have naïve epistemological beliefs are those who think that knowledge is certain, simple and it is derived by who has the authority. It is obtained quickly or without any phase as well, and ability in learning is a gift of birth. Otherwise, those who have a sophisticated belief like to consult a variety of learning source, able to integrate the ideas, and keep trying if they encounter difficulties in a task [9]. Epistemological beliefs were assumed as a system of more or less independent dimensions. These dimensions are: (1) Structure of Scientific Knowledge (SSK); (2) Nature of Knowing and Learning (NKL); (3) Real- Life Applicability (RLA); (4) Evolving Knowledge (EK); and (5) Source of Ability to Learn (SAL) [10].

Empirical studies revealed that there is a relationship between epistemological beliefs and metacognition. For example, sophisticated beliefs are associated with self-reported monitoring strategies [11]. Enrichment metacognition will affect individual sophisticated epistemological beliefs [12] Personal epistemological beliefs can significantly affect an operation of cognitive and metacognitive [13], [14]. Ref. [10] showed that students with sophisticated belief show a metacognitive behavior.

Metacognition plays an important role in learning. Metacognition is a cognitive ability that is necessary to achieve deep and meaningful learning [15]. Ref. [16] suggested metacognition should be taught to the student in a physics course. Metacognition refers to a student's knowledge about their cognition process and the ability to control and monitoring the process. There are two essential components of metacognition: knowledge and control. Metacognition knowledge refers to what students understand about a subject matter or a task, and the decisions they make by using all cognitive resources as a result of the knowledge. Metacognitive control is regard to attention resources, cognitive strategy, and awareness of breakdowns which all enhanced by metacognitive knowledge and skills [17]. Metacognitive skills concern the procedural knowledge that is required for the actual regulation of and control over one's learning activities. Task analysis, goal setting, planning, monitoring, checking, and recapitulation are manifestations of such skills. [18]. 
Ref. [19] reported that metacognitive skills are necessary for problem-solving. Ref. [20] suggested that metacognition skills should be taught to the student. The student should be able to predict their ability to perform the task and current levels of their understanding. Veenman and Spaans stated four categories of metacognitive skills in problem-solving: 1) orientation, 2) planning, 3) evaluation (regulation, monitoring, and checking), and 4) elaboration [21]. This research used metacognition skills which are reading, planning, analyze, calculating, and answering. In each category containing the element of metacognitive skill such as monitoring, reflecting, regulating, justifying, and evaluating.

The correlation between epistemological beliefs and metacognition skills, encourage researchers to investigate the skills during the solving physics problem. We provide an overview of students' metacognitive skills in problem-solving according to the level of their epistemological beliefs.

\section{METHOD}

This research applied qualitative-descriptive approach. Subjects in this study were three students of high school in Palu, Indonesia. They were between $15-17$ years old. Epistemological belief data were collected used EBAPS (Epistemological Beliefs Assessment for Physical Science). EBAPS was developed by Ref. [22]. This questionnaire contains 30 multiple choice questions which designed to measure epistemological beliefs based on five dimensions of personal epistemologies. Each item was scored on a scale of 0 (least sophisticated) to 4 (most sophisticated) following a prescribed scoring grid [10]. This instrument was translated into the Indonesian Language.

EBAPS questionnaire has been given to 50 high school students. Based on EBAPS scores, we choose three respondents to represent the sophisticated, moderate and naïve belief. Questionnaire and interviews results were analyzed to find out the description of respondents' epistemological belief. Name of respondent obfuscated by giving the RS code for respondents with sophisticated epistemological belief, RM and RN for respondents with moderate and naïve belief. Respondents were asked to solve 5 physics problems, and during those activities, they expressed verbally or write down what are they think (thinking-aloud method). After finished one question, respondent was interviewed about their steps. It was way to reinforce and assist us in determining the respondents' metacognition skills. Problem-solving activities were recorded using a video camera. The thinking-aloud transcript then translated in order to obtain a description of respondents' metacognition skills.

\section{RESULT AND DISCUSSION}

Based on EBAPS, three respondents obtained a score which categorizes them into sophisticated, moderate, and naive. Table 1 shows the EBAPS score of the respondents.
TABLE 1. EBAPS SCORES OF RESPONDENTS'

\begin{tabular}{|c|c|c|c|c|c|c|c|}
\hline \multirow{2}{*}{ No } & \multirow{2}{*}{ Code } & \multicolumn{5}{|c|}{ Epistemological Dimensions } & \multirow{2}{*}{ Mean } \\
\cline { 3 - 7 } & & SSK & NKL & RLA & EK & SAL & \\
\hline 1 & RS & 61,3 & 85,9 & 93,8 & 25,0 & 65,0 & 66,2 \\
\hline 2 & RM & 60,0 & 64,1 & 56,3 & 33,3 & 36,3 & 50,0 \\
\hline 3 & RN & 42,5 & 22,5 & 25,0 & 47,5 & 27,5 & 33,0 \\
\hline
\end{tabular}

Based on EBAPS score in each dimension, it can be seen epistemological belief category from each respondent in table 2 .

TABLE 2. EPISTEMOLOGICAL BELIEF OF RESPONDENTS

\begin{tabular}{|c|c|c|c|}
\hline $\begin{array}{c}\text { Epistemological } \\
\text { Beliefs } \\
\text { Dimensions }\end{array}$ & RS & RM & RN \\
\hline SSK & Moderate & Moderate & Moderate \\
\hline NKL & Sophisticated & Sophisticated & Naïve \\
\hline RLA & Sophisticated & Moderate & Naïve \\
\hline EK & Naïve & Naïve & Moderate \\
\hline SAL & Sophisticated & Moderate & Naïve \\
\hline General Category & Sophisticated & Moderate & Naïve \\
\hline
\end{tabular}

\section{Description of Respondents' Metacognition in Problem Solving}

\section{1) Sophisticated Epistemological Beliefs of Respondent (RS)}

RS began to solve the problem with reading the question while setting information from the problem and write down on the answer sheet. He always monitored and reflecting his understanding with representing the information, used his own words or draw a sketch. He also justifies and regulates his plans (question number 2, 4, and 5), it indicated he knew what steps he would do to solve the problem. RS always monitored when calculations his answer (monitoring problem information and equation). He also regulating (question number 1) justifying (question number 2) and checking (question number 5 ). When he got the results, RS always interpret the meaning of the answers (except Question 5). He did re-examine the results and calculation process because he felt a mistake after evaluating the results of the answers he got (question number 5). He monitored and justified the concept (question number 3 and 5), then changed the plan and the process of calculation.

Example of RS's statement in question number 5:

$7 \quad$...wait the $\mathrm{F}$ is $20 \mathrm{~N}$, right? (reflecting)

8 if she pressed a tin down (monitoring)

9 I think we can use the third law (justifying)

17 so, the acceleration is zero

19 ... wait, lets me draw (checking)

26 it means, the force is 70 Newton (interpreting)

27 it's that true (evaluating)

In general, RM's problem solving pattern is presented in Figure 1.

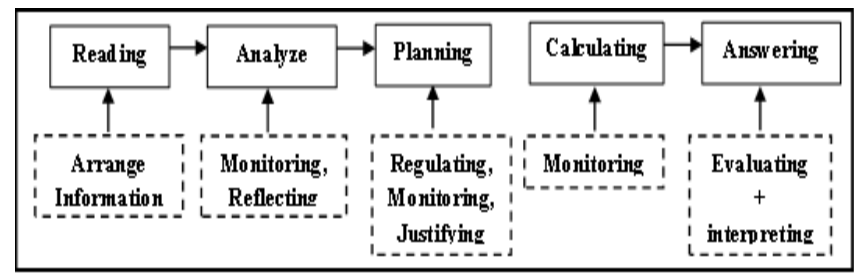

Fig. 1. Pattern of Physics Problem Solving for RS 
2) Moderate Epistemological Beliefs Respondent (RM)

RM's steps in solving the problem generally were begun with a reading question while managing information from the problem. During the process, he monitored his understanding by representing the information into a sketch. After reading the questions, he did not show explicitly his analysis. He immediately determined the equation that will be used (Question 1). RM monitored the purpose of the question while he was calculating the final answer. He evaluated his answer by asking himself. Probably, he was not sure about his answer. However, RM did not follow up by re-examining the calculation step what he had done.

Example of RS's statement in question number 2:

4 Acceleration, mass...Force to mass (Reflecting)

5 ah, I think I don't know

9 Eeh... F $=\mathrm{m} \times \mathrm{a}$

11 Force, acceleration

$12 \mathrm{Ah}, \mathrm{I}$ don't know

In general, RM's problem-solving pattern is presented in Figure 2.

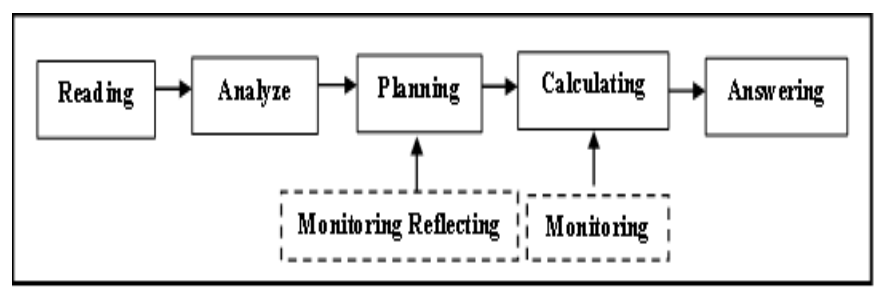

Fig. 2. Pattern of Physics Problem Solving for RM

\section{3) Naive Epistemological Beliefs Respondent (RN)}

$\mathrm{RN}$ was begun to analyze problems after reading the questions by monitored and reflect her understanding of information and interpretation of the question. She writes the information in answer sheet and into a sketch (question number 5). RN expressed her inability to solve the problem in several times. She used trial and error strategy when calculating to solve the problem (except problem number 5). She did not check her plan she has made previously. RN also never checked her steps when she got a final answer. She only checked the unit of her answer and considers the answer she got wrong (question number 2), but then she ignored it. So, I cannot state that is metacognition skill.

Example of RN's Statement in question Number 5:

5 This is a table, right mam?

6 Here a Tin (drawing)(monitoring)

75 Kilo, it means Force and Weight (reflecting)

8 if she pressed down the tin

9 it's five and then 20

11 well.

12 Kilogram, eh doesn't matter

13 Newton Kilogram

In general, RN's problem solving pattern is presented in Figure 3,

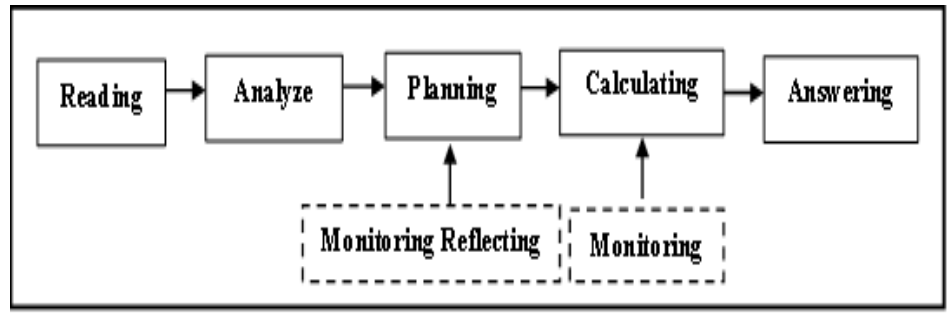

Fig. 3. Pattern of Physics Problem-Solving for RN

Problem-solving strategies are more complex in nature than cognitive strategies. Problem-solving strategy instruction usually focuses on either the development of a general problem-solving strategy or situated practice using that strategy [23]. Polya suggested to solving the problem, students should begin by understanding the problem through a set of information obtained and then create an image for a better understanding of the situation. Second, is devising a plan, what will do to solving the problem. The third is doing calculating, (checking every step and calculating according to the plan). The final step is looking back, checking the final answer, and the problem solution [24]. Polya also suggested that in addition to checking out the steps they did, students also have to prove that the move is correct.

RS Solving the problems in line what is suggested by Polya. The all main categories and elements of metacognition skills: monitoring, regulating, reflecting, evaluating and justifying, has been raised by the RS. However, the checking was only RS did when he completed question number 5 . Respondents with moderate and naïve belief (RM and RN) did not bring out all of the metacognition skill elements. They only showed generally monitoring comprehension, concept or equation that will be used in problem-solving. Their reflecting skill was confined to reflect their inability to solving the problem. It is different with RS which also monitor and justify his plans when solving the problem. RM actually also did justify (Question number 3 and 5), but the equation and work plans were unrelated to the question. So, because of his lack of understanding and knowledge, the justifying steps did not produce an accurate solution to solve the problem. RN never showed justify in all stages of problem-solving.

Based on the general pattern that emerged metacognition skill categories of respondents with different beliefs, the respondents with a sophisticated epistemological belief raised the main categories of metacognition skills when did problemsolving. But specifically for evaluating this respondent did not consistently appear. He also regulates the plan and justifies it. It is generally not done by the respondents with moderate epistemological beliefs and Naïve. The only RC was performed required inspection (checking) when got the answer. The checking is an important step in the process of problemsolving. Checking at the end, useful for identifying a mistake in calculation and all steps in problem-solving. RM and RN only reflected their final answer, but not for tried to monitor their problem-solving progress and checking the answer.

Pulmones stated that students with naïve epistemological beliefs tend to choose a learning strategy that asks right or wrong answer. Therefore, instead of building their own 
understanding, they choose to learn by memorizing. Their Naïve beliefs do not encourage students for seeking strategies to understand so that they can build their own knowledge. Students with naïve beliefs also showed less persistence on problem-solving [10]. It is also found among respondents with moderate epistemological beliefs and naïve in this study. They directly reflect their inability when faced with difficult problems. They also showed a quitter attitude and lacking in patience.

\section{CONCLUSIONS}

Based on the data analysis, it could be concluded that students with sophisticated epistemological beliefs showed all of the main categories and elements of metacognition skills (monitoring, reflecting, regulating, justifying and evaluation). All elements were not shown by the two student categories.

\section{ACKNOWLEDGMENTS}

We would like to thank Directorate of Higher, Ministry of National Education and Culture of Indonesia for funding this publication in Hibah Tim Pascasarjana 2017 contract number: 696c/UN28.2/PL/2017. Secondly, we wish to thank I Komang Werdhiana for this validation and valuable discussion.

\section{REFERENCES}

[1] B. K. Hofer and G. M. Sinatra, "Epistemology, metacognition, and selfregulation: musings on an emerging field," Springer, vol. 5, no. 1, pp. 113-120, 2009.

[2] M. Schommer-Aikins, O. K. Duell, and R. Hutter, "Epistemological Beliefs, Mathematical Problem-Solving Beliefs, and Academic P ...," 2005.

[3] D. E. Alvermann, Gaoyin Qian, "Relationship Between Epistemological Beliefs and Conceptual Change Learning," Read. Writ. Q., vol. 16, no. 1, pp. 59-74, Jan. 2000.

[4] R. M. Del Rosario and A. B. I. Bernardo, "Personal Epistemologies and Motivation in Schools: The Relationship Between Students' Epistemological Beliefs and Intrinsic Motivation in Learning," pp. 277307, 2012.

[5] M. M. Alpaslan, B. Yalvac, C. C. Loving, and V. Willson, "Exploring the Relationship Between High School Students' Physics-Related Personal Epistemologies and Self-regulated Learning in Turkey," Int. J. Sci. Math. Educ., vol. 14, no. 2, pp. 297-317, Mar. 2016.

[6] V. Cifarelli, T. Goodson-espy, and J. Chae, "Victor Cifarelli," J. Adv. Acad., vol. 21, no. 2, pp. 204-232, 2010.

[7] H. Adnan, A. Correspondence, Halis, and A. Arslantaş, "Epistemological Beliefs and Academic Achievement," J. Educ. Train. Stud., vol. 4, no. 1, 2016.
[8] M. Sahin, "Correlations of Students ' Grades, Expectations, Epistemological Beliefs and Demographics in a Problem-Based Introductory Physics Course," vol. 4, no. 2, pp. 169-184, 2009.

[9] S. L. Nist and J. P. Holschuh, "Practical Applications of the Research on Epistemological Beliefs," J. Coll. Read. Learn., vol. 35, pp. 84-92.

[10] R. Pulmones, "Linking Students' Epistemological Beliefs with Their Metacognition in a Chemistry Classroom," Asia-Pacific Educ. Res., vol. 19, no. 1, pp. 143-159, 2010.

[11] R. Bromme, S. Pieschl, and E. Stahl, "Epistemological beliefs are standards for adaptive learning: a functional theory about epistemological beliefs and metacognition," Metacognition Learn., vol. 5, no. 1, pp. 7-26, Apr. 2010.

[12] E. Akar, "The Interplay Between Metacognitive Awareness and Epistemological Beliefs," 2011, pp. 978-605.

[13] Ching Sing, C. S. Chai, M. S. Khine, and T. Teo, "Epistemological Beliefs on Teaching and Learning: A Survey among Pre-Service Teachers in Singapore,” EMI. Educ. Media Int., vol. 43, no. 4, pp. 285298, 2006.

[14] P. C. Jena and L. Ahmad, "Meta cognitive Strategy Usage and Epistemological Beliefs of Primary School Teacher Trainees: An Explorative Study," vol. 9, pp. 1-10, 2013.

[15] D. Garrison and Z. Akyol, "Toward the development of a metacognition construct for communities of inquiry," Elsevier, vol. 24, pp. 66-71, 2014.

[16] G. Schraw, "Promoting general metacognitive awareness A framework for understanding metacognition," Instr. Sci., vol. 26, pp. 113-125, 1998.

[17] T. Gok, "The General Assessment of Problem Solving Processes and Metacognition in Physics Education," Eurasian Journal Phys. Chem. Educ., vol. 2, no. 2, pp. 110-122, 2010.

[18] M. Van Der Stel, M. V. J. Veenman, M. Van Der Stel, and M. V. J. Veenman, "Metacognitive skills and intellectual ability of young adolescents: a longitudinal study from a developmental perspective," Eur J Psychol Educ, vol. 29, pp. 117-137, 2014.

[19] A. Henderson et al., "Instructors' Ideas about Problem Solving Setting Goals," in Proceedings of Physics Education Research Conference, 2001.

[20] J. P. Mestre, "Implications of research on learning for the education of prospective science and physics teachers," vol. 36, 2000.

[21] M. V. J. Veenman and M. A. Spaans, "Relation between intellectual and metacognitive skills: Age and task differences," Learn. Individual. Differ., vol. 15, pp. 159-176, 2005.

[22] "Idea Behind EBAPS." [Online]. Available: http://www2.physics.umd.edu/ elby/EBAPS/idea.htm. [Accessed: 13Apr-2017].

[23] G. Schraw, K. J. Crippen, and K. Hartley, "Promoting Self-Regulation in Science Education: Metacognition as Part of a Broader Perspective on Learning," Res. Sci. Educ. White Mitchell, vol. 36, pp. 111-139, 2006.

[24] G. Polya, "How to Solve It," The Mathematical Gazette, vol. 30. p. 181, 1945. 